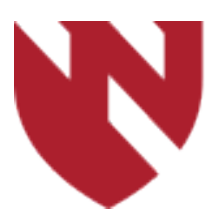

\title{
Comparing Outcomes in Out of Hospital Cardiac Arrest After Implementing Mechanical Compression Devices
}

\author{
Jonathan Weseman \\ University of Nebraska Medical Center \\ Eric Ernest \\ University of Nebraska Medical Center \\ Abraham Campos \\ University of Nebraska Medical Center \\ Aaron Barksdale \\ University of Nebraska Medical Center \\ Elizabeth Lyden \\ University of Nebraska Medical Center
}

Tell us how you used this information in this short survey.

Follow this and additional works at: https://digitalcommons.unmc.edu/gmerj

Part of the Higher Education Commons, and the Medicine and Health Sciences Commons

\section{Recommended Citation}

Weseman, J., Ernest, E., Campos, A., Barksdale, A., , Lyden, E. Comparing Outcomes in Out of Hospital Cardiac Arrest After Implementing Mechanical Compression Devices. Graduate Medical Education Research Journal. 2020 Sep 29; 2(1). https://digitalcommons.unmc.edu/gmerj/vol2/iss1/86 
Comparing Outcomes in Out of Hospital Cardiac Arrest After Implementing Mechanical Compression Devices

\section{Creative Commons License}

\section{(c) (1) $\Theta(9$}

This work is licensed under a Creative Commons Attribution-Noncommercial-No Derivative Works 4.0 License. 


\section{Comparing Outcomes in Out of Hospital Cardiac Arrest After Implementing Mechanical Compression Devices \\ Jonathan Weseman ${ }^{1}$, Eric Ernest ${ }^{1}$, Abraham Campos ${ }^{1}$, Aaron Barksdale ${ }^{1}$, Elizabeth Lyden ${ }^{2}$ \\ ${ }^{1}$ University of Nebraska Medical Center, Department of Emergency Medicine \\ ${ }^{2}$ University of Nebraska Medical Center, College of Public Health, Department of Biostatistics}

\section{Mentor: Eric Ernest}

Program: Emergency Medicine

Type: Original Research

Background: Out of hospital cardiac arrests (OHCA) are a common problem globally and occur with a rate of 50-100 per 100,000 person years. Survival rates in OHCA are low, averaging around $7 \%$. Numerous factors are associated with increased OHCA survival rates, with one of the strongest being return of spontaneous circulation (ROSC) at hospital admission. Improvements made to achieving ROSC have potential to decrease mortality in OHCA. This study aims to determine if there is a difference in achieving sustained ROSC using mechanical cardiopulmonary resuscitation (CPR) devices as opposed to standard CPR in OHCA. Secondary objectives evaluated demographic variables, witnessed arrest, bystander CPR, AED use, and initial rhythm for associations with
ROSC, survival, and Cerebral Performance Category (CPC).

Methods: This retrospective cohort study utilized the Cardiac Arrest Registry to Enhance Survival (CARES) registry to analyze all OHCA in patients greater than 18 years of age from 9/1/16 through 9/30/18, in a metropolitan area of nearly one million people. Exclusion criteria were traumatic cardiac arrest and known active do not resuscitate (DNR) order. Mechanical CPR devices included in the registry were the Lund University Cardiopulmonary Assist System (LUCAS) and AutoPulse. Descriptive statistics and Fisher's exact test were used.

Results: In total, 544 patients were included in the study; 347 (64\%) were male, with an average age of 63 years. Overall 176 (32\%) received standard CRP, 200 (37\%) mechanical CPR via LUCAS, and 168 (31\%) via AutoPulse. Sustained ROSC was achieved in $168(31 \%)$ patients: $69(41 \%)$ in the standard CPR group, 60 (36\%) in LUCAS group, and 39 (23\%) with the AutoPulse. There was a statistically significant difference in acquiring ROSC when comparing traditional CPR versus AutoPulse (41\% vs. $23 \%, p=0.0017)$ and borderline significance for CPR versus LUCAS ( $41 \%$ vs. $36 \%$, $\mathrm{p}=0.065)$, but no difference between LUCAS and Autopulse devices $(\mathrm{p}=0.16)$. Witnessed arrest was associated with increased ROSC $(22 \%$ vs $8 \%, \mathrm{P}=0.0004)$ and survival ( $11 \%$ vs $3 \%, p=0.0004)$. No other variables described were associated with ROSC, survival, or improved neurologic outcomes.

Conclusion: There was a statistically significant increase in ROSC for patients who received standard CPR versus mechanical CPR, but no significant difference between the LUCAS and AutoPulse devices.

https://doi.org/10.32873/unmc.dc.gmerj.2.1.085

\section{Screen Media Use in Pediatrics: A QI Project to Promote Behavioral Change}

Taylor Kratochvil', Michelle Wineinger ${ }^{2}$, Danielle Saner ${ }^{2}$, Cristina Fernandez ${ }^{2}$

${ }^{1}$ University of Nebraska Medical Center, College of Medicine

2University of Nebraska Medical Center, Department of Pediatrics

Mentor: Cristina Fernandez

Program: Pediatrics

Type: Original Research

Background: Children are growing up in an increasingly digital world. As mobile devices and digital screens become more accessible, greater attention is paid to screen media use and its effect on pediatric development. The American Academy of Pediatrics (AAP) and the World Health Organization (WHO) have released recommended screen time limits for children and emphasize the importance of high-quality screen media when used. In 2016, the AAP released the Family Media Plan: an online tool for families to create personalized strategies to manage screen media use. The aim of this quality improvement (QI) project is to determine whether screen media use can be reduced in the pediatric population through patient counseling and use of a take-home goal sheet, adapted from the AAP's Family Media Plan.
Methods: Thirty-eight children, ages 6 to 13 , agreed to participate in this study. Preintervention hours of screen media use per week was collected. The Media Use Plan, a summarized, print version of the AAP's Family Media Plan, was developed and distributed to study participants' families. One month later, families were contacted to complete a post-intervention telephone interview.

Results: Of the 38 patients that consented to participate in the study, 35 completed both pre- and post-intervention surveys. The median screen time per week decreased from 16 to 12 hours $(\mathrm{p}<0.0001)$ after pediatrician counseling and Media Use Plan intervention.

Conclusion: Our data suggests that engaging patients in goal-oriented discussions with assistance of the Media Use Plan tool was effective in promoting behavioral change and reducing screen time per week.

https://doi.org/10.32873/unmc.dc.gmerj.2.1.086 